http://dx.doi.org/10.32929/2446-8355.2018v27n4p424-439

\title{
INFLUÊNCIA DO SISTEMA DE SEMEADURA E DA APLICAÇÃO DE FUNGICIDAS SOBRE A PRODUTIVIDADE E QUALIDADE SANITÁRIA DE MILHO
}

\author{
José Roberto Chaves Neto ${ }^{1 *}$, Renato Carnellosso Guerra ${ }^{2}$, Ricardo Boscaini ${ }^{3}$, Nívea Raquel \\ Ledur $^{4}$, Maurivan Travessini ${ }^{5}$, Ivan Francisco Dressler da Costa ${ }^{6}$
}

\begin{abstract}
${ }^{1}$ Engenheiro Agrônomo, M.Sc., Doutorando do Programa de Pós-Graduação em Engenharia Agrícola, Universidade Federal de Santa Maria (UFSM), Campus de Santa Maria; Prédio $42-1^{\circ}$ andar, Cep: 97.105-900, Camobi, Santa Maria, RS, Brasil. *E-mail do autor correspondente: jose.chavesneto@gmail.com.

${ }^{2}$ Engenheiro Agrônomo, M.Sc., TIMAC Agro, Santa Maria, RS, Brasil.

${ }^{3}$ Engenheiro Agrônomo, M.Sc., Doutorando do Programa de Pós-Graduação em Engenharia Agrícola, Universidade Federal de Santa Maria (UFSM), Departamento de Engenharia Rural, Santa Maria, RS, Brasil.

${ }^{4}$ Engenheira Agrônoma na Universidade Federal de Santa Maria (UFSM), Departamento de Defesa Fitossanitária, Santa Maria, RS, Brasil.

${ }^{5}$ Engenheiro Agrônomo, Cooperativa Agrícola Mista Sul Riograndense (CAMSUL), Santa Maria, RS, Brasil. ${ }^{6}$ Engenheiro Agrônomo, Dr., Professor do Departamento de Fitossanidade, Centro de Ciências Agrárias Universidade Federal de Santa Maria (UFSM), Santa Maria, RS, Brasil.
\end{abstract}

Recebido: 25/01/2018; Aceito: 14/12/2018

RESUMO: As podridões de grãos e espigas vem gerando um aumento na perda de produtividade a cada safra na cultura do milho. O objetivo deste trabalho foi avaliar a influência do sistema de semeadura e da aplicação foliar de fungicida sobre a produtividade e qualidade sanitária de grãos de milho. $\mathrm{O}$ experimento foi conduzido a campo em blocos casualizados, em esquema fatorial $2 \times 2 \times 4$, correspondente a dois sistemas de semeadura (direta e convencional), dois híbridos e quatro tratamentos, sendo três com aplicação foliar de fungicidas e uma testemunha sem aplicação, em 4 repetições. Os grãos foram avaliados, quanto a produtividade, porcentagem de grãos ardidos e a sanidade de grãos pelo método de "Blotter test". De modo geral, observou-se que a porcentagem de grãos ardidos foi maior no sistema de semeadura direta, menor no híbrido BG7060HR e quando utilizado os fungicidas Elatus ${ }^{\circledR}$ e Abacus $\mathrm{HC}^{\circledR}$. Entre os sistemas de semeaduras, a semeadura direta favorece a incidência de Aspergillus sp. ao passo de que a semeadura convencional não interfere na incidência de Penicillium sp. O híbrido BG7060HR apresentou menor incidência dos fungos Penicillium sp. e Aspergillus sp. O uso do fungicida Elatus ${ }^{\circledR}$, quando aplicado via foliar, resultou em uma menor incidência do fungo Penicillium sp. e em um incremento na produtividade de grãos. O uso dos fungicidas Abacus $\mathrm{HC}^{\circledR}$, Aproach Prima ${ }^{\circledR}$ e Elatus ${ }^{\circledR}$ reduziram a incidência do fungo Aspergillus sp. A produtividade de grãos foi influenciada apenas pelo fator tratamento, sendo mais pronunciada quando utilizado o fungicida Elatus ${ }^{\circledR}$.

Palavras-chave: Controle químico. Incidência de fungos. Podridão da espiga. Grãos ardidos.

\author{
INFLUENCE OF THE SOWING SYSTEM AND THE APPLICATION OF \\ FUNGICIDES ON THE PRODUCTIVITY AND CORE SANITARY QUALITY
}


ABSTRACT: Grain and ear rot has led to an increase in yield loss for each crop in the corn crop. The objective of this work was to evaluate the influence of the sowing system and foliar application of fungicide on the yield and sanitary quality of corn grains. The experiment was conducted in a randomized block design, in a $2 \times 2 \times 4$ factorial scheme, corresponding to two sowing systems (direct and conventional), two hybrids and four treatments, three with foliar application of fungicides and one control without application, in 4 replicates. The grains were evaluated for yield, percentage of burned grains and grain sanity by the blotter test method. In general, it was observed that the percentage of burned grains was higher in the no-tillage system, lower in the BG7060HR hybrid and when the fungicides Elatus ${ }^{\circledR}$ and Abacus $\mathrm{HC}^{\circledR}$ were used. Among the sowing systems, direct sowing favors the incidence of Aspergillus sp. whereas conventional sowing does not interfere with the incidence of Penicillium sp. The BG7060HR hybrid had a lower incidence of fungi Penicillium sp. and Aspergillus sp. The use of the fungicide Elatus ${ }^{\circledR}$, when applied via foliar, resulted in a lower incidence of the fungus Penicillium sp. and an increase in grain yield. The use of the fungicides Abacus $\mathrm{HC}^{\circledR}$, Aproach Prima ${ }^{\circledR}$ and Elatus ${ }^{\circledR}$ reduced the incidence of fungus Aspergillus sp. The grain yield was influenced only by the treatment factor, being more pronounced when using the fungicide Elatus ${ }^{\circledR}$.

Key words: Chemical control. Incidence of fungal. Cob rot. Rot grains.

\section{INTRODUÇÃO}

Em consequência ao estreitamento das relações patógeno-hospedeiro-ambiente, no decorrer dos últimos anos vem sendo observado um aumento da incidência e severidade das doenças na cultura do milho (Zea mays L.). Segundo Sabato et al. (2013), um fato que vem fazendo com que as podridões de grãos e espigas venham gerando um aumento na perda de produtividade a cada safra, é a pratica de cultivar híbridos com diferentes níveis de resistência, aos fungos causadores destas doenças (SILVA et al., 2014).

A presença de fungos toxigênicos nos grãos ou em produtos deles desenvolvidos, não implica na presença de micotoxinas, uma vez que, para que estes fungos produzam estas substancias é necessária a combinação de condições ambientais, como a alternância das temperaturas diurna e noturna (MENDES et al., 2012).

A utilização de híbridos resistentes a doenças de grãos, a rotação de cultura, uso adequado da irrigação e a aplicação na dose e época correta de fungicidas, são importantes ferramentas contra estas doenças, uma vez que, o plantio direto é uma realidade, a irrigação vem sendo inserida no manejo dos campos de produção de milho e a monocultura ainda é uma pratica utilizada, o que favorece a sobrevivência, a manutenção e a multiplicação do inóculo destes fungos (PILETTI et al., 2014; GARCÉS-FIALLOS; FORCELINI, 2013). Lanza et al. (2016), ao avaliarem a eficiência da aplicação foliar de fungicidas na redução da incidência de patógenos fúngicos, em grãos de milho, relataram a incidência de fungos dos gêneros Fusarium sp., Penicillium sp., Stenocarpella sp. e Aspergillus sp.

Com base nestas considerações o presente trabalho teve como objetivo avaliar a influência do sistema de semeadura e da aplicação foliar de fungicida sobre dois híbridos 
comerciais de milho, quanto ao complexo grãos ardidos e a incidência de fungos (teste de sanidade - Blotter test) nos grãos.

\section{MATERIAL E MÉTODOS}

O experimento foi conduzido, na safra agrícola de 2014/2015, no município de Cruz Alta, região centro-norte do Rio Grande do Sul, a $452 \mathrm{~m}$ de altitude, a latitude $28^{\circ} 51^{\prime}$ '49" S e longitude 53 $31^{\circ}$ '40" O. O período de condução dos experimentos foi de 17/09/2014 até 14/03/2015. O clima predominante do município de Cruz Alta, segundo classificação de Köppen (1948), é do tipo Cfa definido como úmido em todas as estações do ano, verão quente e moderadamente quente. O solo da área experimental é classificado como Latossolo Vermelho Distrófico típico (EMBRAPA, 2013a).

O experimento foi implantado na primeira quinzena do mês de setembro de 2014 e a colheita ocorreu na primeira quinzena de fevereiro de 2015, quando os grãos apresentavam umidade média de 18,8\% (CRUZ et al., 2013). Foram utilizados dois híbridos de milho (BG7051H e BG7060HR), diferindo em relação a tolerância a doenças relacionadas aos grãos, baseado em dados fornecidos pelas empresas produtoras de sementes BioGene (2015), responsável pela produção de sementes destes híbridos, classifica o híbrido BG7051H como susceptível e o híbrido BG7060HR como moderadamente resistente.

O experimento foi implantado e conduzido em delineamento em blocos casualizados (DBC), em esquema fatorial $2 \times 2 \times 4$, correspondente a dois sistemas de semeadura (direta e convencional), dois híbridos e quatro tratamentos, sendo três com aplicação foliar de fungicidas e uma testemunha sem aplicação, em 4 repetições. O experimento totalizou 32 parcelas experimentais. Cada parcela era constituída por quatro linhas de 10,0 m com espaçamento de $0,50 \mathrm{~m}$, ocupando uma área de $20 \mathrm{~m}^{2} /$ parcela, totalizando a área do ensaio de aproximadamente $640 \mathrm{~m}^{2}\left(0,064 \mathrm{ha}^{-1}\right)$.

Metade da área do experimento foi preparada para o sistema de semeadura direta, sobre restos da cultura de inverno (aveia + nabo forrageiro) e a outra metade para o sistema de semeadura convencional, onde o preparo do solo constituiu-se de uma gradagem média e outra leve, na véspera da implantação do experimento. Os híbridos foram semeados em 17/09/2014, com auxílio de uma semeadora-adubadora de quatro linhas, com espaçamento de 0,50 m entre linhas e densidade de 8-10 sementes por metro linear, objetivando uma população estimada de 65.000 plantas ha' ${ }^{-1}$.

A adubação de base foi realizada no sulco da semeadura, com aplicação de $300 \mathrm{~kg} \mathrm{ha}^{-1}$ da fórmula 09-26-14 de N, $\mathrm{P}_{2} \mathrm{O}_{5}$ e $\mathrm{K}_{2} \mathrm{O}$ e cobertura com aplicação de $300 \mathrm{~kg}^{-1}$ ha de sulfato de amônio. Durante a condução do experimento, foram empregadas práticas agrícolas desde a preparação do solo e tratamento de sementes até o controle de plantas daninhas e insetos pragas, quando necessário, para manutenção da cultura, seguindo as recomendações propostas para a cultura na região (EMBRAPA, 2013b).

Os fungicidas testados são apresentados na Tabela 1, a aplicação foliar dos fungicidas, foi realizada no estádio fenológico de V8 (oito folhas completamente desenvolvidas), aproximadamente 60 dias após a emergência das plântulas (DAE), com o auxílio de um 
pulverizador costal/manual, pressurizado com $\mathrm{CO}_{2}$, com barra 04 bicos do tipo leque (RX11002/TEEJET), espaçados 0,50 m, atingindo faixa aplicação de 2,0 m, uma pressão de trabalho de 40 libras.pol ${ }^{-2}$ e uma velocidade de caminhamento de $1 \mathrm{~m} . \mathrm{s}^{-1}$.

Tabela 1. Fungicidas utilizados no experimento e seus ingredientes ativos e doses. Fungicides used in the experiment and their active ingredients and doses.

\begin{tabular}{|c|c|c|c|}
\hline Tratamentos (i.a) & Produto Comercial & $\begin{array}{l}\text { Concentração } \\
\left(\mathrm{g} \text { a.i L }{ }^{-1}\right)\end{array}$ & Concentração \\
\hline Testemunha & --- & --- & --- \\
\hline Piraclostrobina + Epoxiconazol & Abacus HC ${ }^{\circledR}$ & $(333+167)$ & $380 \mathrm{~mL} \mathrm{ha}^{-1}$ \\
\hline Picoxistrobina + Ciproconazole & Aproach Prima $^{\circledR}$ & $(80+200)$ & $300 \mathrm{~mL} \mathrm{ha}^{-1}$ \\
\hline Azoxistrobina + Benzovindiflupir & Elatus $^{\circledR}$ & $(300+150)$ & $150 \mathrm{~g} \mathrm{ha}^{-1}$ \\
\hline
\end{tabular}

A colheita das espigas foi realizada manualmente, em seguida estas foram desempalhadas e debulhadas manualmente e os grãos homogeneizados configurando amostras compostas, oriunda das quatro repetições a campo para cada híbrido, respeitando os tratamentos realizados a campo. Posteriormente estas foram identificadas, armazenadas, e conduzidos a Clínica Fitossanitária (CF) do Departamento de Defesa Fitossanitária do Centro de Ciências Rurais da Universidade de Santa Maria, onde formam submetidas as avaliações de:

Incidência de grãos ardidos (\%): determinada conforme procedimento proposto na portaria $n^{\circ} 11$, de 12/04/96 (BRASIL, 1996), este método consiste na separação visual e pesagem dos grãos com sintomas de descoloração dos grãos provocada pelo desenvolvimento fúngico, em mais de um quarto da sua superfície total, dados expressos em porcentagem.

Sanidade de grãos: realizada de acordo com o método do papel filtro (Blotter test), recomendado para análise de sementes pelo Ministério da Agricultura (BRASIL, 2009). Foram utilizados 25 grãos em oito repetições de cada amostra composta, estes foram distribuídas no interior de gerbox plástico, previamente limpo com álcool etílico 70\%, contendo uma camada de três folhas de papel filtro autoclavada e umedecidas em água destilada, em câmara de fluxo laminar, posteriormente os recipientes foram armazenados em câmara de crescimento sob iluminação contínua, à temperatura de $25 \pm 2{ }^{\circ} \mathrm{C}$, por um período de nove dias. Após este período os fungos foram identificados e contados. A identificação dos fungos, em nível de gênero, presentes nos grãos de milho, foram realizadas com o auxílio de lupa estereoscópica, microscópio ótico com preparação microscópica de cada fungo, além do auxílio de literatura específica (BARNETT; HUNTER, 1998).

Para avaliação de eficácia de cada fungicida utilizou-se a fórmula proposta por Abbott (1925):

$$
\mathrm{E} \%=\frac{\mathrm{T}-\mathrm{F}}{\mathrm{T}} \mathrm{x} 100
$$

Onde: $\mathrm{T}=$ Incidência média na testemunha $(\%) ; \mathrm{F}=$ Incidência média nos tratamentos $(\%) ; \mathrm{E} \%=$ Percentual de eficácia de cada tratamento avaliado.

Os resultados foram submetidos ao teste de normalidade e homogeneidade dos erros, e posteriormente ao teste $\mathrm{F}$ da análise de variância (ANOVA). As médias foram comparadas 
pelo teste Tukey, adotando-se o nível de $5 \%$ de probabilidade de erro $(\mathrm{p} \leq 0,05)$. Foi utilizado o programa estatístico Sisvar versão 5.6 (FERREIRA, 2014) para as análises.

\section{RESULTADOS E DISCUSSÃO}

Na Tabela 2, está apresentado o resumo da análise de variância e os valores médios da porcentagem de grãos ardidos, incidência e percentual de eficácia dos tratamentos no controle dos fungos do gênero Penicillium sp., e Aspergillus sp. e produtividade ( $\mathrm{kg} \mathrm{ha}^{-1}$ ) de grãos de milho envolvendo dois sistemas de semeadura (direta e convencional). A porcentagem de grão ardidos sofreu influência de todos os fatores estudados, assim como das interações sistema de semeadura $\mathrm{x}$ tratamento e híbrido x tratamento (Tabela 2).

Notou-se uma resposta diferenciada dos sistemas de semeadura, conforme a presença de grãos ardidos (Tabela 2). Verificou-se que a maior incidência de grãos ardidos foi detectada no sistema direta, com $13,10 \%$, sendo o menor percentual para o sistema de semeadura convencional com 9,69\% (Tabela 2). Juliatti et al. (2007) obtiveram média de porcentagem de grãos ardidos semelhante para 8 híbridos de milho, com médias variando de 2,15 a 13,03\%, no sistema de semeadura direta, para a região do triângulo mineiro em Minas Gerais.

Para a comparação entre os híbridos, a maior incidência de grãos ardidos foi para o híbrido BG7051H, diferindo estatisticamente do hibrido BG7060HR, que apresentou a menor incidência (Tabela 2). Esses resultados confirmam os níveis de resistência dos híbridos estudados neste experimento as principais doenças, dentre elas as doenças de grãos, publicados pela empresa produtora das sementes desses híbridos BioGene, que classifica o híbrido BG7060HR como moderadamente resistente e o híbrido BG7051H como suscetível.

Em relação a comparação geral entre os tratamentos, constatou-se que ocorreu redução na incidência de grãos ardidos em função da aplicação de fungicidas via foliar, visto que houve diferença estatística entre os tratamentos (Tabela 2). $\mathrm{O}$ fungicida que resultou na menor incidência foi o Elatus ${ }^{\circledR}$, com $6,00 \%$ de grãos ardidos, valor igual ao máximo tolerado pela legislação brasileira (BRASIL, 2009). O tratamento testemunha foi o que obteve maior porcentagem de grãos ardidos, com 22,99 \%, diferindo dos demais tratamentos (Tabela 2). Estes dados são semelhantes aos relatados por Juliatti et al. (2007), os quais verificaram que a aplicação de fungicidas, proporcionou redução na incidência de grãos ardidos, sendo que entre os fungicidas testados, o que proporcionou a menor incidência foi o Piraclostrobina + Epoxiconazole.

O complexo grãos ardidos em milho, é consequência da incidência e severidade das podridões de espigas, que tem como principais agentes causais, os fungos mais frequentemente detectados e associados ao complexo "grãos ardidos" são Fusarium moniliforme, Fusarium verticillioides, Fusarium graminearum, Penicillium oxalicum, Gibberella zeae, Stenocarpella maydis e Stenocarpella macrospora (MENDES, 2012; RIZZARDI et al., 2017). Neste trabalho foi detectado fungos dos gêneros Penicillium sp. e Aspergillus sp. 
Tabela 2. Resumo da análise de variância e valores médios de grãos ardidos (GA - \%), porcentagem de incidência e percentual de eficácia dos tratamentos no controle dos fungos Penicillium sp., e Aspergillus sp. e produtividade (PROD - $\mathrm{kg} \mathrm{ha}^{-1}$ ) de grãos de milho envolvendo dois sistemas de semeadura (direta e convencional). Summary of analysis of variance and mean values of burned grains (GA -\%), percentage of incidence and percentage of treatments efficacy in the control of fungi Penicillium sp., And Aspergillus sp. and yield (PROD - kg ha-1) of corn grains involving two sowing systems (direct and conventional).

\begin{tabular}{|c|c|c|c|c|c|c|}
\hline \multirow[b]{2}{*}{ Tratamentos } & \multirow[b]{2}{*}{ Grãos ardidos (\%) } & \multicolumn{4}{|c|}{ Sanidade de Grãos } & \multirow{2}{*}{$\begin{array}{c}\text { PROD } \\
\left(\mathrm{kg} \mathrm{ha}^{-1}\right)\end{array}$} \\
\hline & & \multicolumn{2}{|c|}{$\begin{array}{l}\text { Penicillium sp. } \\
(\%)\end{array}$} & \multicolumn{2}{|c|}{$\begin{array}{c}\text { Aspergillus sp. } \\
(\%)\end{array}$} & \\
\hline $\mathrm{F}^{1}$ & \multicolumn{6}{|c|}{ Quadrado Médio (QM) } \\
\hline Semeadura (S) & $139,61 *$ & \multicolumn{2}{|c|}{$7938,00^{*}$} & \multicolumn{2}{|c|}{$684,50 *$} & $1602665,8^{\mathrm{NS}}$ \\
\hline Híbrido (H) & $59,052 *$ & \multicolumn{2}{|c|}{$16928,00^{*}$} & \multicolumn{2}{|c|}{$144,50 *$} & $593747,5^{\mathrm{NS}}$ \\
\hline Tratamento $(\mathrm{T})$ & $736,56^{*}$ & \multicolumn{2}{|c|}{$6841,00^{*}$} & \multicolumn{2}{|c|}{$517,83^{*}$} & $16816432,7 *$ \\
\hline $\mathrm{S} * \mathrm{H}$ & $1,00^{\mathrm{NS}}$ & \multicolumn{2}{|c|}{$11250,00^{*}$} & \multicolumn{2}{|c|}{$112,50^{\mathrm{NS}}$} & $2161803,7^{\mathrm{NS}}$ \\
\hline $\mathrm{S} * \mathrm{~T}$ & $262,22 *$ & \multicolumn{2}{|c|}{$3113,67 *$} & \multicolumn{2}{|c|}{$335,17 *$} & $413776,3^{\mathrm{NS}}$ \\
\hline $\mathrm{H}^{*} \mathrm{~T}$ & $114,00 *$ & \multicolumn{2}{|c|}{$7562,33 *$} & \multicolumn{2}{|c|}{$17,83^{\mathrm{NS}}$} & $751157,4^{*}$ \\
\hline $\mathrm{S} * \mathrm{H}^{*} \mathrm{~T}$ & $4,51^{\mathrm{NS}}$ & \multicolumn{2}{|c|}{$1975,67 *$} & \multicolumn{2}{|c|}{$12,50^{\mathrm{NS}}$} & $325029,3^{\mathrm{NS}}$ \\
\hline $\mathrm{CV}(\%)$ & 19,34 & \multicolumn{2}{|c|}{33,56} & \multicolumn{2}{|c|}{30,19} & 15,33 \\
\hline \multicolumn{7}{|c|}{ Sistema de Semeadura } \\
\hline Direta & $13,10 b$ & \multicolumn{2}{|c|}{$21,75 b$} & \multicolumn{2}{|c|}{$5,25 b$} & $5520,00 \mathrm{a}$ \\
\hline Convencional & $9,69 \mathrm{a}$ & \multicolumn{2}{|c|}{$6,00 \mathrm{a}$} & \multicolumn{2}{|c|}{$0,63 \mathrm{a}$} & $5203,51 \mathrm{a}$ \\
\hline $\mathrm{CV}(\%)$ & 20,42 & \multicolumn{2}{|c|}{19,64} & \multicolumn{2}{|c|}{24,64} & 12,39 \\
\hline \multicolumn{7}{|l|}{ Híbrido } \\
\hline BG7051H & $12,50 \mathrm{~b}$ & \multicolumn{2}{|c|}{$25,38 b$} & \multicolumn{2}{|c|}{$4,00 \mathrm{~b}$} & $5458,08 \mathrm{a}$ \\
\hline BG7060HR & $10,28 \mathrm{a}$ & & & & $88 \mathrm{a}$ & $5265,44 a$ \\
\hline $\mathrm{CV}(\%)$ & 23,08 & 18 & & & 5,2 & 11,85 \\
\hline Tratamento & & & Efc. $(\%)^{3}$ & & Efc. $(\%)$ & \\
\hline Testemunha & $22,99 \mathrm{c}$ & $33,63 d$ & 0,00 & $8,88 \mathrm{~b}$ & 0,00 & $4643,06 b$ \\
\hline Abacus $\mathrm{HC}^{\circledR}$ & $7,32 \mathrm{ab}$ & $16,00 \mathrm{c}$ & 52,42 & $1,88 \mathrm{a}$ & 78,87 & $4964,46 b$ \\
\hline Aproach Prima ${ }^{\circledR}$ & $9,17 \mathrm{~b}$ & $4,88 \mathrm{~b}$ & 85,50 & $0,13 \mathrm{a}$ & 98,59 & $4956,42 b$ \\
\hline Elatus $^{\circledR}$ & $6,00 \mathrm{a}$ & $1,00 \mathrm{a}$ & 97,03 & $0,88 \mathrm{a}$ & 90,14 & $6883,08 \mathrm{a}$ \\
\hline $\mathrm{CV}(\%)$ & 20,33 & 19 & & & 42 & 15,36 \\
\hline
\end{tabular}

Médias seguidas de mesmas letras na coluna não diferem estatisticamente entre si pelo Teste de Tukey, em nível de significância de 5\%. (1) Teste F, (2) Eficácia dos tratamentos. * significativo a 5\% e (NS) não significativo. *Averages followed by the same letters in the column do not differ statistically from each other by the Tukey test, at a significance level of 5\%. ${ }^{(1)}$ Test $F,^{(2)}$ Efficacy of treatments. * significant at $5 \%$ and ${ }^{(N S)}$ not significant.

Os resumos das análises de variância e os valores médios para incidência de fungos dos gêneros Penicillium sp. e Aspergillus sp. em grãos de milho, envolvendo dois sistemas de semeadura (direta e convencional), em experimento com irrigação, estão apresentados na Tabela 2. Para a incidência do fungo Penicillium sp. constatou-se diferença significativa para sistemas de semeadura, híbridos, tratamentos, e para a interação sistemas de semeadura $\mathrm{x}$ híbridos, sistema de semeadura x tratamentos, híbridos x tratamentos, e para interação tripla 
sistemas de semeadura x híbridos x tratamentos. Quanto a incidência do fungo Aspergillus sp. observou-se diferença significativa para todas as fontes de variações, e para interação semeadura $\mathrm{x}$ tratamento (Tabela 2).

A precisão experimental avaliada pelo coeficiente de variação $(\mathrm{CV})$ variou entre as características. O maior valor de CV foi observado para a incidência de Penicillium sp. $(33,56 \%)$ e o menor, para produtividade de grãos $(15,33 \%)$ (Tabela 2$)$.

Quanto ao fator sistema de semeadura, de maneira geral, os valores médios de incidência dos fungos dos gêneros Penicillium sp., e Aspergillus sp., foram maiores no sistema de semeadura direta (Tabela 2). Os resultados obtidos neste trabalho corroboram com os relatados por Mendes et al. (2011), que verificaram maior incidência de fungos no sistema de semeadura direta.

Estes resultados estão relacionados ao fato de que no sistema de semeadura direta é deixado sobre o solo os restos da cultura anterior, que associado a característica necrotrófica dos fungos causadores de doenças relacionadas aos grãos de milho proporciona uma maior fonte de inóculo, e poderão ocasionar uma maior infecção nos grãos produzidos, além disso as condições climáticas da região Sul do Brasil são favoráveis para o desenvolvimento destes fungos (MELO et al., 2013; SABATO et al., 2013).

Para o fator híbrido verificou-se que, a maior incidência dos fungos Penicillium sp. e Aspergillus sp. concentraram-se no híbrido BG7051H (Tabela 2). Devido a elevadas porcentagens de incidência de fungos do gênero Penicillium sp., permite inferir que existe diferença entre os híbridos avaliados e que os mesmos possuem comportamento diferente para os fungos em estudos. Este comportamento entre híbridos também foi relatado por Mendes et al. (2011), que ao avaliar pelo teste de sanidade (Blotter test) a incidência de fungos em grãos de milho, oriundos de híbridos comerciais, verificaram diferença estatística entre os híbridos. Rizzardi et al. (2017), também reportaram diferenças quanto a resistência entre híbridos quando submetidos à presença ou ausência da inoculação do fungo Stenocarpella maydis.

É importante enfatizar que, o híbrido considerado susceptível (BG7050H) ao complexo "grãos ardidos", foi o que apresentou os maiores valores de incidência dos fungos Penicillium sp. e Aspergillus sp. Estes resultados confirmam a diferença genética entre os híbridos estudados neste experimento, de acordo com as características agronômicas disponibilizadas pela empresa BioGene (2015) responsável pela produção de sementes destes híbridos.

Quanto ao fator tratamento observou-se que, para a incidência de fungos dos gêneros Penicillium sp. o tratamento Elatus ${ }^{\circledR}$ foi o que proporcionou o maior controle, com eficácia média de $97,03 \%$. O menor controle foi observado no tratamento testemunha, que foi de 33,63\% para incidência do fungo Penicillium sp. (Tabela 2).

Para os resultados da incidência do fungo Aspergillus sp., o tratamento que apresentou a maior incidência foi a Testemunha, com 8,88\%, a menor porcentagem foi verificada no tratamento Aproach Prima ${ }^{\circledR}$, com $0,13 \%$, não diferindo estatisticamente dos tratamentos Abacus $\mathrm{HC}^{\circledR}$ e Elatus ${ }^{\circledR}$ (Tabela 2).

Os fungos identificados no teste de sanidade de grãos realizado neste trabalho estão de acordo com Lanza et al. (2016) e Mendes et al. (2012), que identificaram em grão de milho 
quatro gêneros de fungos associados aos grãos, sendo dois presentes neste trabalho: Penicillium sp. e Aspergillus sp.

Estes dados são semelhantes aos citados por Stefanello et al. (2012), que ao verificarem a influência da aplicação do fungicida Azoxistrobina + Ciproconazol, via folia, na presença de fungos, em grãos de milho, também verificaram grande incidência de fungos do gênero Penicillium sp.

Para a produtividade de grãos houve significância $(\mathrm{P} \leq 0,05)$ apenas para $\mathrm{o}$ fator tratamento e para interação híbrido x tratamento (Tabela 2), constatou-se que o tratamento Elatus $^{\circledR}$, proporcionou a maior produtividade, com média $6883,08 \mathrm{~kg} \mathrm{ha}^{-1}$, sendo os demais tratamentos estatisticamente semelhantes. A influência da aplicação de fungicidas sobre a produtividade também foi observado por Estes valores de produtividade estão de acordo com as médias do Estado do Rio Grande do Sul, que são inferiores a $6.560 \mathrm{~kg} \mathrm{ha}^{-1}$ para a mesma safra agrícola 2014/15 (Companhia Nacional de Abastecimento, CONAB, 2015). Vilela et al. (2012), que ao avaliarem o comportamento de diferentes híbridos de milho em função da aplicação foliar de dois fungicidas, constataram que a aplicação foliar de fungicidas no prépendoamento da cultura, proporcionou ganhos de produtividade.

Ao analisar o desdobramento dos sistemas de semeadura em relação aos tratamentos para à porcentagem de grãos ardidos (Tabela 3), pode-se inferir que os tratamentos com aplicação de fungicidas tiveram respostas diferentes quando aplicados sobre plantas vindas do sistema de semeadura direta e convencional.

Tabela 3. Desdobramento da interação sistema de semeadura $x$ tratamento referente à porcentagem de grãos ardidos, envolvendo dois sistemas de semeadura (direta e convencional). Deployment of the sowing system interaction $x$ treatment referring to the percentage of burned grains, involving two sowing systems (direct and conventional).

\begin{tabular}{ccc}
\hline \multirow{2}{*}{ Tratamentos } & \multicolumn{2}{c}{ Sistemas de Semeadura } \\
\cline { 2 - 3 } & Direta & Convencional \\
\hline Testemunha & $14,47 \mathrm{bA}$ & $31,51 \mathrm{cB}$ \\
Abacus HC® & $7,80 \mathrm{aA}$ & $6,84 \mathrm{abA}$ \\
Aproach Prima ${ }^{\circledR}$ & $8,43 \mathrm{aA}$ & $9,91 \mathrm{bA}$ \\
Elatus ${ }^{\circledR}$ & $8,05 \mathrm{aA}$ & $4,14 \mathrm{aA}$ \\
\hline
\end{tabular}

Médias seguidas de mesmas letras, minúscula na coluna e maiúscula na linha, não diferem estatisticamente entre si pelo Teste de Tukey, em nível de significância de 5\%. Means followed by the same letters, lowercase in the column and upper case in the row, do not differ statistically from each other by the Tukey test, at a significance level of $5 \%$.

No sistema de semeadura direta houve diferença significativa entre os tratamentos e testemunha, onde o tratamento Abacus $\mathrm{HC}^{\circledR}$ obteve a menor porcentagem de grãos ardidos $(7,80 \%)$ e a testemunha $(14,47 \%)$, porém entre os fungicidas não houve diferença estatística dos tratamentos Abacus HC®, Elatus ${ }^{\circledR}$ e Aproach Prima ${ }^{\circledR}$. Para o sistema de semeadura convencional, também houve diferença significativa entre os tratamentos, o tratamento que apresentou a menor incidência de grãos ardidos foi o Elatus ${ }^{\circledR}$, com 4,14\%, porém não diferindo estatisticamente do tratamento Abacus $\mathrm{HC}^{\circledR}$, mas diferindo do tratamento Aproach Prima $^{\circledR}$, e o maior percentual foi obtido no tratamento Testemunha com $31,51 \%$, diferindo 
estatisticamente dos tratamentos com aplicação de fungicida (Tabela 3). Os resultados encontrados neste trabalho demonstram a eficácia do uso de fungicida na melhoria da qualidade dos grãos.

A eficácia dos fungicidas estrobilurinas em mistura com triazóis, também foi relatada por Juliatti et al. (2007), que observaram redução da incidência de grãos ardidos quando aplicou-se o fungicida Azoxistrobina + Ciproconazol. Brito et al., (2012), ao avaliarem o efeito da aplicação de fungicidas no controle da Cercosporiose, da Mancha branca do milho e na incidência de grãos ardidos, constataram que o uso do fungicida Azoxistrobina + Cyproconazol reduziu significativamente a incidência de grãos ardidos.

A eficácia destes fungicidas a campo foi descrita por Garcés-Fiallos e Forcelini (2013), que ao avaliarem a eficácia de fungicidas triazóis e suas misturas com estrobilurinas no controle a campo da Ferrugem asiática, constataram que a mistura de triazol + estrobilurina foi a que apresentou um controle mais efetivo. Juliatti et al. (2014) e Chaves Neto, et al., (2017), ao avaliarem a eficácia de diferentes fungicidas no controle da mancha branca do milho, uma doença também associada a podridão de espigas e grãos, observaram que os fungicidas formulados a partir da mistura de estrobilurinas com triazóis apresentaram eficácia superior a $90 \%$ no controle da doença.

Quanto ao desdobramento da interação híbrido x tratamento (Tabela 4), observou-se diferença significativa entre os tratamentos para ambos os híbridos estudados.

Tabela 4. Desdobramento da interação híbrido $x$ tratamento referente à porcentagem de grãos ardidos, envolvendo dois sistemas de semeadura (direta e convencional). Deployment of the hybrid interaction $x$ treatment referring to the percentage of burned grains, involving two sowing systems (direct and conventional).

\begin{tabular}{ccc}
\hline \multirow{2}{*}{ Tratamentos } & \multicolumn{2}{c}{ Híbridos } \\
\cline { 2 - 3 } & BG7051H & BG7060HR \\
\hline Testemunha & $28,59 \mathrm{bB}$ & $17,39 \mathrm{bA}$ \\
Abacus HC® & $5,91 \mathrm{aA}$ & $8,73 \mathrm{aA}$ \\
Aproach Prima ${ }^{\circledR}$ & $9,23 \mathrm{aA}$ & $9,11 \mathrm{aA}$ \\
Elatus ${ }^{\circledR}$ & $6,28 \mathrm{aA}$ & $5,91 \mathrm{aA}$ \\
\hline
\end{tabular}

Médias seguidas de mesmas letras, minúscula na coluna e maiúscula na linha, não diferem estatisticamente entre si pelo Teste de Tukey, em nível de significância de 5\%. Means followed by the same letters, lowercase in the column and upper case in the row, do not differ statistically from each other by the Tukey test, at a significance level of $5 \%$.

Com base nos valores do híbrido BG7051H, o tratamento Abacus $\mathrm{HC}^{\circledR}$ foi o que obteve a menor porcentagem de grãos ardidos, com 5,91\%, não diferindo estatisticamente dos tratamentos Aproach Prima ${ }^{\circledR}$ e Elatus ${ }^{\circledR}$, o maior percentual foi obtido no tratamento Testemunha, com 28,59\% (Tabela 4).

Para o híbrido BG7060HR, o tratamento que apresentou a menor incidência de grãos ardidos foi o Elatus ${ }^{\circledR}$, com $5,91 \%$ de grãos ardidos, não diferindo estatisticamente dos tratamentos Abacus $\mathrm{HC}^{\circledR}$ e Aproach Prima ${ }^{\circledR}$. O tratamento Testemunha, foi o que obteve a maior porcentagem, com 17,39\% (Tabela 4). 
Ao avaliar o desdobramento dos tratamentos dentro dos híbridos, constatou-se que, no tratamento testemunha o híbrido BG7051H obteve a maior incidência de grãos ardidos, com 28,59\%, diferindo estatisticamente do híbrido BG7060HR, que obteve a menor porcentagem, com 17,39\% (Tabela 4), muito embora esse efeito não tenha sido evidenciado nos demais tratamentos, uma vez que não houve diferenças significativas entre os híbridos.

Resultados semelhantes foram encontrados Gonçalves et al., (2012), observaram que a aplicação foliar de fungicidas têm um grande potencial na redução da incidência e severidade de doenças, e além do aumento no rendimento de grãos, ocorreu redução da incidência dos grãos ardidos.

Analisando o desdobramento dos híbridos dentro dos tratamentos, verificou-se que, não houve diferenças significativas entre os híbridos em ambos os tratamentos com fungicidas estudados (Tabela 4).

A significância da interação sistemas de semeadura $\mathrm{x}$ híbridos $\mathrm{x}$ tratamentos, para à incidência do fungo Penicillium sp., permite inferir que há diferenças na reação dos híbridos avaliados quanto a aplicação foliar dos fungicidas testados neste ensaio e que isso é dependente dos sistemas de semeadura (Tabela 5).

Tabela 5. Desdobramento da interação sistema de semeadura $x$ híbrido $x$ tratamento referente à incidência de fungos do gênero Penicillium sp. (\%), envolvendo dois sistemas de semeadura (direta e convencional). Deployment of the sowing $x$ hybrid system $x$ treatment referring to the incidence of fungi of the genus Penicillium sp. (\%), involving two sowing systems (direct and conventional).

\begin{tabular}{ccccc}
\hline \multirow{2}{*}{ Tratamentos } & \multicolumn{4}{c}{ Sistemas de Semeadura } \\
\cline { 2 - 5 } & \multicolumn{3}{c}{ Direta } & \multicolumn{3}{c}{ Cóbridos } \\
\cline { 2 - 5 } & BG7051H & BG7060HR & BG7051H & BG7060 \\
\cline { 2 - 5 } & $99,00 \mathrm{cB}$ & $1,50 \mathrm{aA}$ & $31,00 \mathrm{bB}$ & $3,00 \mathrm{aA}$ \\
\hline Testemunha & $62,50 \mathrm{bB}$ & $0,50 \mathrm{aA}$ & $1,00 \mathrm{aA}$ & $0,00 \mathrm{aA}$ \\
Abacus HC & ${ }^{\circledR}$ & $13,50 \mathrm{bA}$ & $0,50 \mathrm{aA}$ & $0,50 \mathrm{aA}$ \\
Aproach Prima $^{\circledR}$ & $5,00 \mathrm{aA}$ & $0,00 \mathrm{aA}$ & $0,00 \mathrm{aA}$ & $0,00 \mathrm{aA}$ \\
Elatus $^{\circledR}$ & $4,00 \mathrm{aA}$ & &
\end{tabular}

Médias seguidas de mesmas letras, minúscula na coluna e maiúscula na linha, não diferem estatisticamente entre si pelo Teste de Tukey, em nível de significância de 5\%. Means followed by the same letters, lowercase in the column and upper case in the row, do not differ statistically from each other by the Tukey test, at a significance level of $5 \%$.

De maneira geral, os valores médios de incidência do fungo Penicillium sp., foram maiores no sistema de semeadura direta, quando comparado com os valores obtidos no sistema de semeadura convencional (Tabela 5).

De acordo com Sabato et al. (2013), sistema de semeadura direta sobre a palha e o monocultivo são práticas culturais que, associadas à natureza necrotrófica dos fungos causadores de doenças relacionadas aos grãos de milho, contribuem positivamente para a permanência e aumento do inóculo a cada safra de cultivo. Tendo como agravante, o fato de que a região Sul do país apresenta condições ambientais favoráveis para o desenvolvimento desse fungo (MENDES et al., 2012; RIZZARDI et al., 2017). 
No sistema de semeadura direta houve diferença significativa entre os tratamentos para ambos os híbridos avaliados. Para os resultados do híbrido BG7051H, o tratamento Elatus ${ }^{\circledR}$ apresentou a menor incidência do fungo Penicillium sp., com 4,00\%, não diferindo estatisticamente do tratamento Aproach Prima ${ }^{\circledR}(5,00 \%)$, e a maior incidência foi observada no tratamento Testemunha, com 99,00\%. Para o híbrido BG7060HR o tratamento Elatus ${ }^{\circledR}$ obteve a menor porcentagem de incidência do fungo Penicillium sp., com 0,00\%, não diferindo dos tratamentos Abacus $\mathrm{HC}^{\circledR}$ e Testemunha. O tratamento Aproach Prima ${ }^{\circledR}$, foi o que apresentou a maior incidência, com 13,50\% (Tabela 5).

Stefanello et al. (2012), ao avaliarem a influência da aplicação do fungicida Azoxistrobina + Ciproconazol via foliar quanto a presença de fungos, em grãos de milho, constataram que a pulverização de plantas de milho com fungicida Azoxistrobina + Ciproconazol não resultou em menor incidência do fungo Penicillium sp. nos grãos.

Quanto ao sistema de semeadura convencional, houve diferença significativa entre os tratamentos apenas para o híbrido BG7051H. A menor incidência do fungo Penicillium sp. foi para o tratamento Elatus ${ }^{\circledR}$, com $0,00 \%$, não diferindo estaticamente Abacus $\mathrm{HC}^{\circledR}$ e Aproach Prima $^{\circledR}$. O tratamento Testemunha, foi o que apresentou a maior incidência, com $31,00 \%$ (Tabela 5).

Com base na significância da interação sistemas de semeadura x tratamentos, para a incidência do fungo Aspergillus sp., pode-se inferir que as plantas de milho se comportaram de forma diferente quando são submetidas a aplicação de fungicidas via foliar e quanto ao sistema de semeadura (Tabela 6). De modo geral, os valores de incidência do fungo Aspergillus sp., foram superiores no sistema de semeadura direta, para todos os tratamentos avaliados.

Tabela 6. Desdobramento da interação sistema de semeadura $x$ tratamento referente à incidência de fungos do gênero Aspergillus sp. (\%), envolvendo dois sistemas de semeadura (direta e convencional). Deployment of the sowing system interaction $x$ treatment referring to the incidence of fungi of the genus Aspergillus sp. (\%), involving two sowing systems (direct and conventional).

\begin{tabular}{ccc}
\hline \multirow{2}{*}{ Tratamentos } & \multicolumn{2}{c}{ Sistemas de Semeadura } \\
\cline { 2 - 3 } & Direta & Convencional \\
\hline Testemunha & $16,00 \mathrm{bB}$ & $1,75 \mathrm{aA}$ \\
Abacus HC® & $3,00 \mathrm{aA}$ & $0,75 \mathrm{aA}$ \\
Aproach Prima ${ }^{\circledR}$ & $0,25 \mathrm{aA}$ & $0,00 \mathrm{aA}$ \\
Elatus ${ }^{\circledR}$ & $1,75 \mathrm{aA}$ & $0,00 \mathrm{aA}$
\end{tabular}

Médias seguidas de mesmas letras, minúscula na coluna e maiúscula na linha, não diferem estatisticamente entre si pelo Teste de Tukey, em nível de significância de 5\%. Means followed by the same letters, lowercase in the column and upper case in the row, do not differ statistically from each other by the Tukey test, at a significance level of $5 \%$.

Quanto ao desdobramento dos tratamentos em relação ao sistema de semeadura (Tabela 6), constatou-se que os tratamentos com aplicação dos fungicidas Abacus $\mathrm{HC}^{\circledR}$, Aproach Prima ${ }^{\circledR}$ e Elatus ${ }^{\circledR}$ proporcionaram menor incidência do fungo Aspergillus sp. no sistema de semeadura convencional, muito embora esse efeito não tenha sido evidenciado no sistema de 
semeadura convencional, uma vez que, não houve diferenças significativas entre os tratamentos.

Analisando o desdobramento dos sistemas de semeadura dentro dos tratamentos, constatou-se diferença significativa entre os sistemas de semeadura apenas no tratamento testemunha, onde a maior incidência foi observada para o sistema de semeadura direta, com $16,00 \%$, sendo o menor percentual para o sistema de semeadura convencional $(1,75 \%)$ (Tabela 6).

De modo geral, os tratamentos com aplicação dos fungicidas Abacus $\mathrm{HC}^{\circledR}$, Aproach Prima $^{\circledR}$ e Elatus ${ }^{\circledR}$ utilizados neste trabalho, proporcionaram menor incidência do fungo Aspergillus sp. Por outro lado Stefanello et al. (2012), ao avaliarem a influência da aplicação do fungicida Azoxistrobina + Ciproconazol via foliar quanto a presença de fungos, em grãos colhidos de milho, constataram que o uso do fungicida não resultou em menor incidência do fungo Aspergillus sp. nos grãos. O mesmo comportamento foi observado por Small et al. (2012), que relatam ausência de efeito da aplicação destes fungicidas.

Analisando o desdobramento da interação dos tratamentos em relação aos híbridos para a produtividade de grãos (Tabela 7), verificou-se diferença significativa entre os tratamentos em ambos os híbridos estudados.

Tabela 7. Desdobramento da interação híbrido $\mathrm{x}$ tratamento referente à produtividade de grãos $\left(\mathrm{kg} \mathrm{ha}^{-1}\right)$, envolvendo dois sistemas de semeadura (direta e convencional). Hybrid interaction split $x$ treatment for grain yield $\left(\mathrm{kg} \mathrm{ha}^{-1}\right)$, involving two sowing systems (direct and conventional).

\begin{tabular}{ccc}
\hline \multirow{2}{*}{ Tratamentos } & \multicolumn{2}{c}{ Híbridos } \\
\cline { 2 - 3 } & BG7051H & BG7060HR \\
\hline Testemunha & $4861,00 \mathrm{bA}$ & $4425,13 \mathrm{bA}$ \\
Abacus HC $^{\circledR}$ & $5214,56 \mathrm{bA}$ & $4714,37 \mathrm{bA}$ \\
Aproach Prima $^{\circledR}$ & $5094,60 \mathrm{bA}$ & $4818,24 \mathrm{bA}$ \\
Elatus $^{\circledR}$ & $6662,14 \mathrm{aA}$ & $7104,02 \mathrm{aA}$ \\
\hline
\end{tabular}

Médias seguidas de mesmas letras, minúscula na coluna e maiúscula na linha, não diferem estatisticamente entre si pelo Teste de Tukey, em nível de significância de 5\%. Means followed by the same letters, lowercase in the column and upper case in the row, do not differ statistically from each other by the Tukey test, at a significance level of $5 \%$.

Com base nos resultados do híbrido BG7051H o tratamento que apresentou maior produtividade foi o com aplicação foliar do fungicida Elatus ${ }^{\circledR}$, com produtividade de 6.662,14 kg.ha ${ }^{-1}$, que foi superior estatisticamente aos tratamentos Testemunha, Abacus $\mathrm{HC}^{\circledR} \mathrm{e}$ Aproach Prima ${ }^{\circledR}$. O mesmo comportamento foi observado entre os tratamentos no híbrido BG7060HR, visto que o tratamento que gerou maior produtividade foi o Elatus ${ }^{\circledR}$, com média de 7.104,02 kg. ha-1, que também diferiu estatisticamente dos demais tratamentos (Tabela 7).

Estes resultados são semelhantes aos citados por Juliatti et al. (2014), que destacam a elevada eficácia das estrobilurinas, que além de reduzir a severidade das doenças promoveu aumento de produtividade, visto que o tratamento mais produtivo foi Azoxistrobina + Ciproconazol. Manerba et al. (2013), também destacam a influência da aplicação de fungicidas sobre a produtividade de grãos, visto que todos os tratamentos com aplicação de 
fungicidas foram superiores à testemunha, destacando-se $\mathrm{o}$ fungicida sistêmico Piraclostrobina + Epoxiconazol, por ter proporcionado um acréscimo na produtividade de $90 \%$ em relação à testemunha e 50\% em relação aos demais tratamentos.

Estes dados corroboram com os citados por Mendes et al. (2012), que ao avaliarem o comportamento de 10 híbridos de milho, submetidos a inoculação dos fungos causadores de podridão de espigas, em dois sistemas de semeadura, convencional e direta, verificaram diferença significativa entre os híbridos considerados resistentes versus os híbridos considerados susceptíveis, para produtividade de grãos. Por outro lado, Vilela et al. (2012) ao avaliarem o desempenho agronômico de híbridos de milho em função da aplicação foliar de fungicidas, não constataram aumento de produtividade de grãos de milho, mesmo tendo sido verificado a redução na incidência e severidade de doenças foliares.

\section{CONCLUSÃO}

De modo geral, a porcentagem de grãos ardidos foi maior no sistema de semeadura direta, menor no híbrido BG7060HR e quando utilizado os fungicidas Elatus ${ }^{\circledR}$ e Abacus $\mathrm{HC}^{\circledR}$.

Há influência do sistema de semeadura, do híbrido, e da aplicação de fungicidas sobre a infecção dos fungos causadores de podridões de espigas. Entre os sistemas de semeaduras, a semeadura direta favorece a incidência de Aspergillus sp. ao passo de que a semeadura convencional não interfere na incidência do fungo Penicillium sp.

O híbrido BG7060HR apresentou menor incidência dos fungos Penicillium sp. e Aspergillus sp. O uso do fungicida Elatus ${ }^{\circledR}$, quando aplicado via foliar, resultou em uma menor incidência do fungo Penicillium sp. O uso dos fungicidas Abacus HC ${ }^{\circledR}$, Aproach Prima ${ }^{\circledR}$ e Elatus ${ }^{\circledR}$ reduziram a incidência do fungo Aspergillus sp.

A produtividade de grãos foi influenciada apenas pelo fator tratamento, sendo mais pronunciada quando utilizado o fungicida Elatus ${ }^{\circledR}$.

\section{AGRADECIMENTOS}

Os autores agradecem a Coordenação de Aperfeiçoamento de Pessoal de Nível Superior (CAPES), pelo auxílio financeiro e pela bolsa de mestrado ao primeiro autor.

\section{REFERÊNCIAS BIBLIOGRÁFICAS}

ABBOTT, W. S. A method of computing the effectiveness of an insecticide. Journal of Economic Entomology, Lanham, v. 18, n. 2, p.265-267, 1925.

BARNETT, H. L.; HUNTER, B. B. Illustrated genera of imperfect fungi. 4. ed. St. Paul, MN: Am. Phytopatol. Soc. Press, 1998. 218 p.

BIOGENE: Híbridos recomendado para as regiões Centro Alto e Sul: Níveis de tolerância as principais doenças. Disponível em: http://www.biogene.com.br/milho/produtos. Acesso em: 15 nov. 2015. 
BRASIL. Ministério da Agricultura e Reforma Agrária. Portaria No 11, de 12 de abril de 1996. Comissão Técnica de Normas e Padrões. Normas de identidade, qualidade, embalagem e apresentação do milho. Brasília, DF. 1996. 13 p.

BRASIL. Ministério da Agricultura, Pecuária e Abastecimento. Secretaria de Defesa Agropecuária. Regras para análise de sementes. Brasília, DF: Mapa/ACS, 2009. 395 p.

BRITO, A. H.; PEREIRA, J. L. A. R.; VON PINHO, R. G.; BALESTRE, M. Controle químico de doenças foliares e grãos ardidos em milho (Zea mays L.). Revista Brasileira de Milho e Sorgo, Sete Lagoas, v. 11, n. 1, p.49-59, 2012.

CHAVES NETO, J. R.; COSTA, I. F. D.; BOSCAINI, R.; LEDUR, N. R.; GUERRA, R. C. Sensibilidade in vitro de fungos isolados de grãos de milho ao fungicida azoxistrobina + benzovindiflupir em diferentes concentrações. Enciclopédia Biosfera, Goiânia, v. 13, n. 23, p.1211-1224, 2016.

CHAVES NETO, J. R.; TRAVESSINI, M.; BOSCAINI, R.; LEDUR, N. R.; COSTA, I. F. D. Eficácia da aplicação foliar de fungicidas no controle de mancha-branca do milho. Revista Tecnologia \& Ciência Agropecuária, João Pessoa, v. 11, n. 1, p.31-36, 2017.

COMPANHIA NACIONAL DE ABASTECIMENTO - CONAB. Acompanhamento da safra brasileira de grãos, v. 2 - Safra 2014/15, n. 11 - Décimo primeiro levantamento, agosto de 2015. Disponível em: 〈http://www.conab.gov.br〉. Acesso em: 20 setembro 2015.

CRUZ, J. C.; PEREIRA FILHO, I. A.; QUEIROZ, L. R. Quatrocentas e sessenta e sete cultivares de milho estão disponíveis no mercado de sementes do Brasil para a safra 2013/14. Sete Lagoas, MG: Embrapa, 2013. Disponível em: < http://www.cnpms.embrapa.br/milho/cultivares/>. Acesso em: 14/11/2017.

EMPRESA BRASILEIRA DE PESQUISA AGROPECUÁRIA - EMBRAPA. Centro Nacional de Pesquisa de Solos. Sistema Brasileiro de Classificação do Solo - SIBCS. 3. ed. Brasília/DF: EMBRAPA / CNPS, 2013. 306 p. (a)

EMPRESA BRASILEIRA DE PESQUISA AGROPECUÁRIA - EMBRAPA. Reunião técnica anual de milho. Indicações técnicas para o cultivo de milho e de sorgo no Rio Grande do Sul safras 2013/2014 e 2014/2015. Brasília/DF: EMBRAPA / CNPS, 2013. 124 p. (b)

FERREIRA, D. F. SISVAR: a Guide for its Bootstrap procedures in multiple comparisons. A computer statistical analysis system. Ciência \& Agrotecnologia, Lavras, v. 38, n. 2, p.109$112,2014$.

GARCÉS-FIALLOS, F. R. FORCELINI, C. A. Controle comparativo da ferrugem asiática da soja com fungicida triazol ou mistura de triazol +Estrobilurina. Bioscience Journal, Uberlândia, v. 29, n. 4, p.805-815, 2013.

GONÇALVES, M. E. M. P.; GONÇALVES JUNIOR, D.; SILVA, A. G.; CAMPOS, H. D.; SIMON, G. A.; SANTOS, C. J. L.; SOUSA, M. A. Viabilidade do controle químico de doenças foliares em híbridos de milho no plantio de safrinha. Nucleus, Ituverava, v. 9, n. 1, p.49-62, 2012. 
JULIATTI, F. C.; BELOTI, I. F.; JULIATTI, B. C. M.; CRATO, F. F. Eficácia da associação de fungicidas e antibióticos no manejo da mancha branca do milho e seu efeito na produtividade. Bioscience Journal, Uberlândia, v. 30, n. 6, p.1622-1630, 2014.

JULIATTI, F. C.; ZUZA, J. L. M. F.; SOUZA, P. P.; POLIZEL, A. C. Efeito do genótipo de milho e da aplicação foliar de Fungicidas na incidência de grãos ardidos. Bioscience Journal, Uberlândia, v. 23, n. 2, p.34-41, 2007.

KÖPPEN, W. Climatologia. México, DF: Fundo de Cultura Económica, 1948. 71 p.

LANZA, F. E.; ZAMBOLIM, L.; COSTA, R. V.; SILVA, D. D.; QUEIROZ, V. A. V.; PARREIRA, D. F.; MENDES, S. M.; SOUZA, A. G. C.; COTA, L. V. Aplicação foliar de fungicidas e incidência de grãos ardidos e fumonisinas totais em milho. Pesquisa Agropecuária Brasileira, Brasília, v. 51, n. 5, p.638-646, 2016.

LOPES, L. N. S.; SILVA, A. S.; PEREIRA, C. C. O.; MENEZES, I. P. P.; MALAFAIA, G.; LIMA, M. L. P. Sensibilidade de isolados de Colletotrichum gloeosporioides a fungicidas. Multi-Science Journal, Urutaí, v. 1, n. 1, p.106-114, 2015.

MANERBA, F. C.; SOUZA, P. E.; PINHO, R. G. V.; DORNELAS, G. A.; MONTEIRO, F. P. Antibióticos no Controle da Mancha Branca do Milho. Comunicata Scientiae, Bom Jesus, v. 4, n. 4, p.361-367, 2013.

MELO, R. S. S.; SILVA, A. S.; SILVA, I. F.; SOUZA, M. A.; SILVA NETO, L. F. Sistemas de culturas com milho sob semeadura direta na região Nordeste do Brasil. Ciência Rural, Santa Maria, v. 43, n. 9, p.1535-1541, 2013.

MENDES, M. C.; PINHO, R. G. V.; MACHADO, J. C.; AlBUQUERQUE, C. J. B.; FALQUETE, J. C. F. Qualidade sanitária de grãos de milho com e sem inoculação a campo dos fungos causadores de podridões de espiga. Ciência \& Agrotecnologia, Lavras, v. 35, n. 5, p.931-939, 2011.

MENDES, M. C.; PINHO, R. G. V.; PINHO, E V. R. V. FARIA, M. V. Comportamento de híbridos de milho inoculados com os fungos causadores do complexo grãos ardidos e associação com parâmetros químicos e bioquímicos. Ambiência, Guarapuava, v. 8, n. 2, p.275-292, 2012.

PILETTI, G. J.; CASA, R. T.; BAMPI, D.; PILETTI, L. M. M. S.; STOLTZ, J. C.; SANGOI, L.; MICHELUTTI, D. Reação de híbridos de milho à mancha-de-mascropora. Summa Phytopathologica, Botucatu, v. 40, n. 1, p.24-28, 2014.

PINTO, N. F. J. A. Grãos ardidos em milho. Sete Lagoas-MG: Embrapa Milho e Sorgo, 2005. 6 p. (Circular técnica 66)

RAMOS, A. T. M.; MORAES, M. H. D.; CARVALHO, R. V.; CAMARGO, LUIS, E. A. Levantamento da microflora presente em grãos ardidos e sementes de milho. Summa Phytopathologica, Botucatu, v. 36, n. 3, p.257-259, 2010.

RIZZARDI, D. A.; FARIA, C. M. D. R.; FARIA, M. V.; MENDES, M. C.; ROSSI, E. S.; FIGUEIREDO, A. S. T.; POSSATO JÚNIOR, O. Artificial com Stenocarpella maydis em 
híbridos de milho. Scientia Agraria Paranaensis, Marechal Cândido Rondon, v. 16, n. 2, p.166-170, 2017.

SABATO, E. O.; PINTO, N. F. J. A.; FERNANDES, F. T. Identificação e controle de doenças na cultura do milho. 2. ed. Brasília: Embrapa, 2013. 198 p.

SILVA, A. G.; TEIXEIRA, I. R.; MARTINS, P. D. S.; SIMON, G. A.; FRANCISCHINI, R. Desempenho agronômico e econômico de híbridos de milho na safrinha. Revista Agroambiente, Boa Vista, v. 8, n. 2, p.261-271, 2014.

SMALL, I. M.; FLETT, B. C.; MARASAS, W. F. O.; MCLEOD, A.; VILJOEN, A. Use of resistance elicitors to reduce Fusarium ear rot and fumonisin accumulation in maize. Crop Protection, Lincoln, v. 41, n. 1, p.1016, 2012.

STEFANELlO, J.; BACHI, L. M. A.; GAVASSONI, W. L.; HIRATA, L. M.; PONTIM, B. C. A. Incidência de fungos em grãos de milho em função de diferentes épocas de aplicação foliar de fungicida. Pesquisa Agropecuária Tropical, Goiânia, v. 42, n. 4, p.476-481, 2012.

TORRES, F. E.; LANGHI, G.; TEODORO, P. E.; RIBEIRO, L. P.; CORRÊA, C. C. G.; OLIVEIRA, E. P. Desempenho de híbridos de milho cultivados em diferentes espaçamentos na região do cerrado brasileiro. Revista de Ciências Agrárias, Lisboa, v. 36, n. 4, p.411-416, 2013.

VILELA, R. G.; ARF, O.; KAPPES, C.; KANEKO F. H.; GITTI, D. C.; FERREIRA, J. P. Desempenho agronômico de híbridos de milho, em função da aplicação foliar de fungicidas.

Bioscience Journal, Uberlândia, v. 28, n. 1, p.25-33, 2012. 